\title{
The Efficacy of Dose Increments of Botulinum Toxin A in the Treatment of Childhood Esotropia
}

This article was published in the following Dove Press journal:

Clinical Ophthalmology

\author{
Fatemah T Alshamlan \\ Halla A Al Abdulhadi \\ Mofi M Alwalmany \\ Khalid S Alotaibi
}

Pediatric Ophthalmology and Strabismus Department, Dhahran Eye Specialist

Hospital, Dhahran, Saudi Arabia
Correspondence: Fatemah T Alshamlan Pediatric Ophthalmology and Strabismus Department, Dhahran Eye Specialist Hospital, P.O. Box 3930I, Dhahran 31942, Saudi Arabia

Email dr_fate82@hotmail.com
Background: Botulinum toxin is known to have a powerful chemodenervation effect, and it is a well-established alternative to incisional surgery for strabismus. This study aims to investigate the efficacy of dose increments of botulinum toxin A (BTA) for the treatment of specific ranges of angle deviation.

Methods: This was a prospective study that included patients presenting with esotropia to Dhahran Eye Specialist Hospital between 2016 and 2020, who were managed by a single surgeon. Botulinum toxin was given in different dosages $(2.5,5,7.5,10$ international units (IU)) according to the size of deviation (11-19, 20-29, 30-39, and $\geq 40$ prism diopters (PD)), respectively. A successful outcome was defined as deviation $\leq 10$ PD in the last visit (a minimum of 6 months) following a single injection.

Results: A total of 56 patients with esotropia were included. The mean pre-treatment angle of deviation was $38.6 \pm 2.5$ PD. BTA injection in a dose of 2.5 IU for the 11-19 PD angle of deviation showed the highest rate of successful outcomes (75\%). According to the type of esotropia, partially accommodative esotropia showed the best response to the use of dose increments (59\%). The incidence of ptosis post-BTA injection was the least $(37.5 \%)$ with the smallest dose (2.5 IU).

Conclusion: BTA usage in dose increments is safe, efficient, and might be more costeffective with less incidence of BTA associated complications. Different esotropia diagnoses have different clinical responses. However, larger studies are necessary to better predict the outcome of using dose increments.

Keywords: esotropia, botulinum toxin A, angle of deviation

\section{Introduction}

Botulinum toxin is a neurotoxin produced by the bacterium Clostridium botulinum, an anaerobic gram-positive organism that blocks acetylcholine release, the principal neurotransmitter at the neuromuscular junction, causing muscle paralysis. ${ }^{1}$ Different strains of Clostridium botulinum produce different toxins and eight serotypes exist, from A-G. In humans, type A, B, and E can cause clinical botulism. ${ }^{1}$ Type A, the most potent biological toxin, and type B are available for clinical use. ${ }^{1,2}$ There are three Botulinum toxin A (BTA) formulations approved by the US food and drug administration (FDA), which are onabotulinum toxin A $\left(\right.$ Botox $^{\circledR} /$ Vistabel $^{\circledR}$ ), abobotulinum toxin A $\left(\right.$ Dysport $^{\circledR} /$ Azzalure $^{\circledR}$ ), and incobotulinum toxin $\mathrm{A}$ (Xeomin ${ }^{\circledR} /$ Bocouture), and one Botulinum toxin B, which is rimabotulinum toxin B (Myobloc ${ }^{\circledR}$ ). In 1981, Scott introduced the therapeutic potential of BTA in strabismus and published the first report on its clinical use. ${ }^{3}$ In 1989, the FDA approved BTA Botox $^{\circledR}$, Allergan Inc, Irvine, California, USA) for the 
therapeutic use in strabismus. ${ }^{2}$ Other indications for the therapeutic use of BTA in ophthalmology include nystagmus, blepharospasm, hemifacial spasm, lid retraction, spastic entropion, as well as periorbital aesthetic use..$^{2,4}$

In strabismus, BTA improves the amount of deviation and can be considered as a stand-alone therapy in horizontal $^{5}$ and vertical strabismus. ${ }^{6}$ The use of BTA showed the highest success rate with partially accommodative esotropia (PAET). ${ }^{7}$

Up to our best knowledge, the literature has not shown any studies investigating the effect of increasing the dose of BTA in a fixed ladder for a specific increase in the amount of angle deviation in childhood esotropia.

The aim of our study is to investigate the efficacy of specific BTA doses in increments of 2.5 international units (IU) for specific ranges of angle deviation in increments of 10 prism diopters (PD).

\section{Methods}

This prospective study was conducted at Dhahran Eye Specialist Hospital, Dhahran, Saudi Arabia, between 2016 and 2020. The Institutional Review Board (IRB) approval and signed informed consent from the parents were obtained in compliance with the Declaration of Helsinki.

Inclusion criteria: Partially accommodative esotropia, infantile esotropia, nonrefractive accommodative esotropia, basic acquired nonaccommodative esotropia, sensory esotropia, sixth nerve palsy, Duane retraction syndrome, thyroid eye disease, with a minimum follow-up duration of 6 months after BTA injection.

Exclusion criteria: Previous strabismus surgery, previous BTA injection, fully accommodative esotropia, other types of acquired nonaccommodative esotropia.

A detailed history of esotropia, including the onset, duration, and intermittency of strabismus, was taken. Past history of treatments for strabismus and amblyopia including glasses, patching, BTA, and incisional strabismus surgery was obtained. Perinatal history, previous medical, surgical, and drug history were also documented.

All patients underwent a thorough examination, including visual acuity measurements, cycloplegic refraction, anterior segment, and posterior segment examination. A complete orthoptic examination was performed by a single orthoptist throughout the study who was blind to the timing and the dosage of BTA. The angles of deviation in the primary position at distance and near were measured with an alternate prism cover test after giving the full optical correction. Krimsky method was used for patients who were unable to fixate due to low visual acuity or for infants who could not fixate at a distant target, for whom only the angle at near was measured. In patients with a high accommodative convergence/accommodation ( $\mathrm{AC} /$ A) ratio, the distant angle was considered since the difference between the angle at distant and the angle at near was corrected with a +3.00 lens. The average between the angle at distance and the angle at near was considered for patients who had a difference between the two angles, yet did not meet the definition of a high AC/A ratio (ie, a near deviation exceeding distance deviation by $10 \mathrm{PD}$ or more).

All patients were evaluated and given BTA (Onabotulinum toxin $\mathrm{A}$, Botox ${ }^{\circledR}$ ) treatment by a single surgeon. The injection was performed under general anesthesia for all patients. Visualization of the anterior ciliary vessels and the medial rectus from under the conjunctiva facilitated accurate injection as the injection was given blindly without electromyogram (EMG) guidance or direct visualization of the muscle. The BTA bottle contained $100 \mathrm{IU}$ and was diluted with $2 \mathrm{~mL}$ of saline. BTA was administered in each eye unless the patient had a restrictive type of strabismus in whom BTA was given to the involved eye. We divided our sample into four groups. The first group had a mean angle of deviation between 11 and 19 PD and received 2.5 IU of BTA in $0.05 \mathrm{~mL}$ of saline in each muscle. The second group had a mean angle of deviation between 20 and 29 PD and received $5 \mathrm{IU}$ of BTA in $0.1 \mathrm{~mL}$ of saline in each muscle. The third group had a mean angle of deviation between 30 and $39 \mathrm{PD}$ and received $7.5 \mathrm{IU}$ of BTA in $0.15 \mathrm{~mL}$ of saline in each muscle. The fourth group had a mean angle of deviation $\geq 40 \mathrm{PD}$ and received $10 \mathrm{IU}$ of BTA in $0.2 \mathrm{~mL}$ of saline in each muscle (Table 1).

The same mode of angle measurements taken pretreatment was also taken post-treatment in every single visit (minimum follow-up of 6 months post the first injection).

Table I BTA Dosages and Their Corresponding Angles of Deviation

\begin{tabular}{|l|l|l|l|l|}
\hline $\begin{array}{l}\text { Angle of } \\
\text { Deviation }\end{array}$ & I I-19 PD & 20-29 PD & 30-39 PD & $\geq \mathbf{4 0 ~ P D ~}$ \\
\hline BTA dose & $\begin{array}{l}2.5 \mathrm{IU} \text { in } \\
0.05 \mathrm{~mL}\end{array}$ & $\begin{array}{l}5 \mathrm{IU} \text { in } \\
0.1 \mathrm{~mL}\end{array}$ & $\begin{array}{l}7.5 \mathrm{IU} \text { in } \\
0.15 \mathrm{~mL}\end{array}$ & $\begin{array}{l}10 \mathrm{IU} \text { in } \\
0.2 \mathrm{~mL}\end{array}$ \\
\hline
\end{tabular}


Successful treatment was defined as achieving a posttreatment angle of deviation $\leq 10 \mathrm{PD}$ in the last visit. (Minimum follow-up of 6 months post the first injection).

The percentage of improvement in the angle of deviation post-BTA injection was calculated for all the patients from the last visit.

Failure of treatment was considered if a second BTA injection was given, an incisional strabismus surgery was performed, or the angle of deviation was more than $10 \mathrm{PD}$.

We evaluated the incidence of ptosis and acquired vertical deviation which is one the most common complications of BTA, in response to dose increments.

Statistical analysis was conducted using STATA 14.2 software. Continuous variables were presented as mean and SD and inter-group differences were compared using $t$-test. Skewed numerical data were presented as median and average rank and between-group differences were compared using the Mann-Whitney $U$-test. Paired numerical data were compared using the paired $t$-test. Categorical variables were presented as number and percentage and differences between groups were compared using Pearson chi-squared test or Fisher's exact test. Ordinal data were compared using the chi-squared test for trend. Paired binary data were compared using the McNemar test, $\mathrm{p}$-values $<0.05$ were considered statistically significant.

\section{Results}

Fifty-six patients with esotropia were included in the study. The mean age was $4.7 \pm 4.4$ years, ranging from 6 months to 25 years. Females represented the majority of the sample accounting for $58.9 \%(n=33)$, while $41.1 \%(n=23)$ were males (Figure 1). The majority of the patients had infantile esotropia $(42.9 \%, n=24)$ or PAET $(39.3 \%, n=22)$, followed by

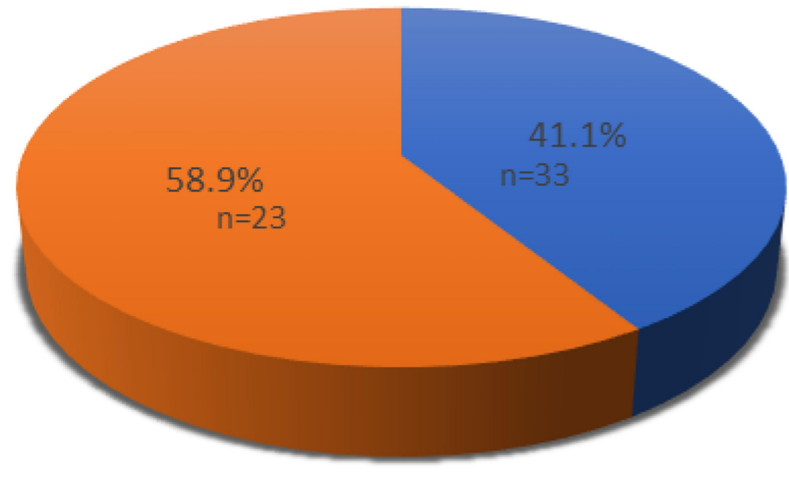

\section{male female}

Figure I Total participants: males $(n=23)$ females $(n=33)$. patients had sensory esotropia $(7.1 \%, \mathrm{n}=4)$ Duane retraction syndrome type $1(3.6 \%, \mathrm{n}=2)$, PAET with a high $\mathrm{AC} / \mathrm{A}$ ratio $(3.6 \%, \mathrm{n}=2)$, nonrefractive accommodative esotropia $(1.8 \%$, $\mathrm{n}=1)$, and bilateral sixth nerve palsy $(1.8 \%, \mathrm{n}=1)$ (Figure 2). The initial mean angle of deviation was $38.6 \pm 2.5 \mathrm{PD}$ (range, 13-90 PD). The follow-up range was 6-33 months.

Eight patients were included in the first group who received 2.5 IU of BTA, 16 patients in the second group, 7 patients in the third group, and 25 patients in the fourth group and they received 5, 7.5, and $10 \mathrm{IU}$, respectively.

The overall success rate was $39.3 \%$. The highest rate of successful treatment was seen in the first group $(75 \%, n=6)$. The second, third, and fourth groups had success rates of $37.5 \%(\mathrm{n}=6), 42.8 \%(\mathrm{n}=3)$, and $28 \%(\mathrm{n}=7)$, respectively. The success rate did not show statistically significant better results for one dose over the others (p-value: 0.13) (Table 2). There was no significant relation between success rate and age or gender (p-value: 0.79 and 0.25 , respectively) (Table 3 ).

The success rate according to the diagnosis was the highest with PAET ( $59.1 \%, \mathrm{n}=13$ ), followed by infantile esotropia $(29.2 \%, n=7)$. One out of the four patients $(25 \%)$ with sensory

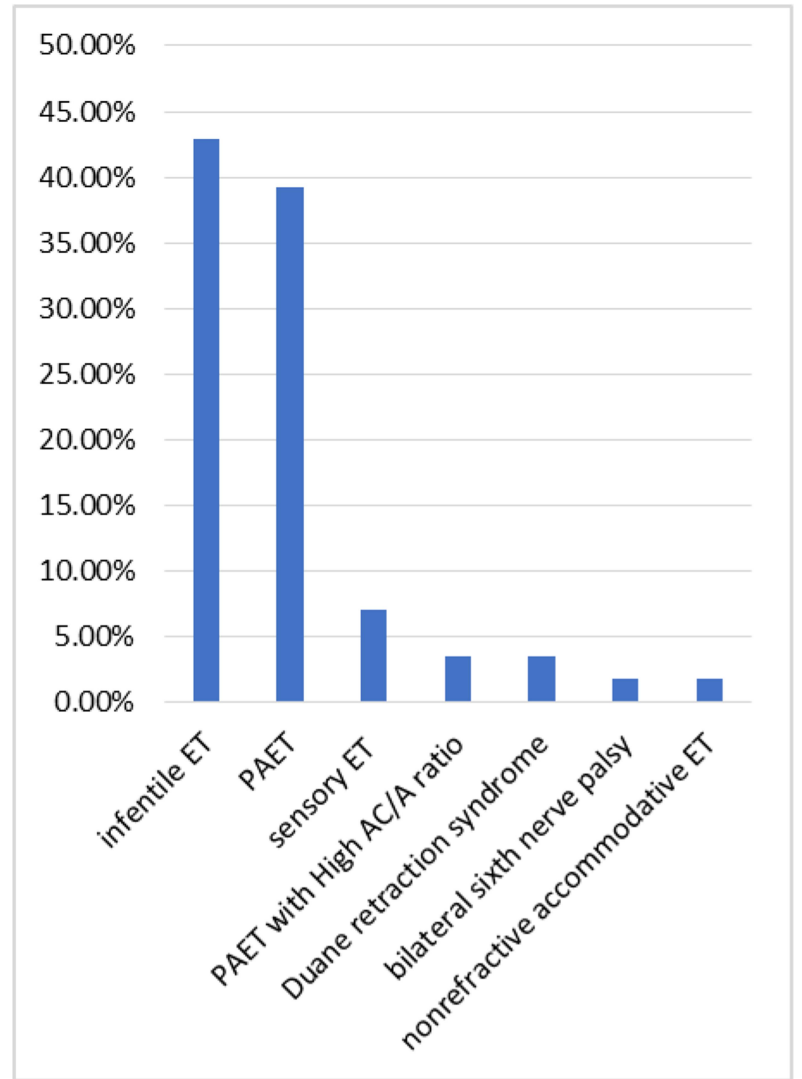

Figure 2 Percentages of the diagnoses from the total number. Abbreviations: ET, esotropia; PAET, partially accommodative esotropia; AC/A, accommodative convergence/accommodation. 
Table 2 Success Rate in Regard to the BTA Dose

\begin{tabular}{|l|l|l|l|l|}
\hline Dose & N \% & Success N \% & Failure N \% & P-value \\
\hline $2.5 \mathrm{IU}$ & $814.3 \%$ & $675 \%$ & $225 \%$ & 0.13 \\
$5 \mathrm{IU}$ & $1628.6 \%$ & $637.5 \%$ & $1062.5 \%$ & \\
$7.5 \mathrm{IU}$ & $712.5 \%$ & $342.8 \%$ & $447.2 \%$ & \\
$\mathrm{I} 0 \mathrm{IU}$ & $2544.6 \%$ & $728 \%$ & $1872 \%$ & \\
\hline
\end{tabular}

Table 3 Success and Failure in Regard to Gender

\begin{tabular}{|l|l|l|l|l|}
\hline Gender & N (\%) & Success N (\%) & Failure N (\%) & P-value \\
\hline Male & $23(41.1 \%)$ & $7(30.4 \%)$ & $16(69.6 \%)$ & 0.25 \\
Female & $33(58.9 \%)$ & $15(45.5 \%)$ & $18(54.6 \%)$ & \\
\hline
\end{tabular}

esotropia and the only patient with bilateral sixth nerve palsy showed successful outcomes, the sixth nerve palsy was chronic. Failed outcomes were seen with both patients who had Duane retraction syndrome type 1, the patient with PAET with a high AC/A ratio, and the only patient with nonrefractive accommodative esotropia. Yet, the approach used in this study did not show statistical significance for one diagnosis over the others (p-value: 0.13) (Table 4).

The mean percentage of angle improvement was more with higher doses of BTA than lower doses, as $57.1 \pm 30.4$ and $45 \pm 31.4$ percentage of improvement in angle deviation were seen with 7.5, and 10 IU of BTA, respectively, in comparison to the lower doses (2.5, and $5 \mathrm{IU})$, which gave $32.1 \pm 41.2$ and $35 \pm 39$ percentage of improvement, respectively (Table 5 ).

In regards to the diagnosis, the highest percentage of improvement $(57.7 \pm 31.5)$ and the highest reduction in angle deviation $(28.8 \pm 15.9)$ were achieved in patients with infantile esotropia (Table 6).

Ptosis, a common temporary adverse effect of BTA, was investigated in all the visits. The overall incidence of ptosis was $50 \%$. Patients who received 2.5 IU of BTA had

Table 4 Success Rate in Regard to the Diagnosis

\begin{tabular}{|l|l|l|l|}
\hline Diagnosis & N & Success N (\%) & P-value \\
\hline Infantile ET & 24 & $729.2 \%$ & 0.13 \\
PAET & 22 & $1359.1 \%$ & \\
Sensory ET & 4 & $125 \%$ & \\
PAET with a high AC/A ratio & 2 & $00 \%$ & \\
Duane retraction syndrome type I & 2 & $00 \%$ & \\
Bilateral sixth nerve palsy & $\mathrm{I}$ & $1 \mathrm{1} 100 \%$ & \\
Nonrefractive accommodative ET & $\mathrm{I}$ & $00 \%$ & \\
\hline
\end{tabular}

Abbreviations: ET, esotropia; PAET, partially accommodative esotropia; AC/A, accommodative convergence/accommodation. the smallest incidence of postoperative ptosis $(37.5 \%$, $\mathrm{n}=3$ ). Postoperative ptosis developed with the use of 5 , $7.5,10$ IU of BTA in $(56.3 \%, n=9),(42.9 \%, n=3)$, and $(52 \%, n=13)$ of patients, respectively. Ptosis resolved from all the patients by 3 months (Table 7). All acquired vertical deviation resolved after 3 months after follow up. All exotropia developed post-BTA injection also resolved by 3 months.

Out of 34 patients who had failed outcome following a single BTA injection, 14 patients had a second BTA injection, and 3 patients decided to go for incisional strabismus surgery.

\section{Discussion}

Up to our knowledge, the effects of increasing the dose of BTA in increments of $2.5 \mathrm{IU}$ for each $10 \mathrm{PD}$ increase in the amount of angle deviation were not investigated in the literature before. Hence, comparing our study to other similar studies was limited. In our prospective study, $39.3 \%$ achieved a significant reduction in angle deviation to $\leq 10 \mathrm{PD}$. The rate of successful outcomes was the highest (75\%) in the first group who had a small angle of deviation (11-19 PD) and was given a small BTA dose (2.5 IU). However, the method used did not show a statistically significant success rate for one dose over the others (p-value: 0.13 ).

Scott et al had 362 patients with childhood strabismus in their study. The initial dose given ranged between 1.0 and 2.5 IU and increased up to $12.5 \mathrm{IU}$ if a successful outcome was not achieved. An average of 1.7 BTA injections for each patient was given and $35 \%$ had prior incisional strabismus surgery. The smaller range of deviation (10-20 PD) had a higher success rate (73\%) than the larger range of deviation (20-110 $\mathrm{PD}, 54 \%)$, defined as a final deviation of $\leq 10 \mathrm{PD}$ at least 6 months post-BTA injection. ${ }^{8}$ These findings are consistent with this study. Abbasoglu et al had 45 patients with esotropia and started with a dose of 2.5 IU of BTA $\left(\right.$ Dysport $^{\circledR}$ ) in a bolus of $0.1 \mathrm{~mL}$ for all the patients regardless of the amount of deviation. Once the outcomes were not satisfactory, the BTA dose was increased to 5, 10, 15, and $20 \mathrm{IU}$, all in $0.1 \mathrm{~mL}$ bolus. They divided their patients into four groups and evaluated the success rate (defined as a stable correction of deviation to within 5 degrees 4 months post-BTA injection) depending on the initial amount of deviation (5-10, 11-15, 16-25, and >25 degrees) where each patient was given an average of 1.7 BTA injection. ${ }^{9}$ Similar to our study, Abbasoglu et al had the highest success rate 
Table 5 The Mean Pre-Treatment and Post-Treatment Deviations, Mean Reduction and Percentage of Improvement from Initial Deviations ( \pm Standard Deviation) with Regard to the Change in BTA Dose

\begin{tabular}{|l|l|l|l|l|l|}
\hline $\begin{array}{l}\text { BTA Dose } \\
\text { (IU) }\end{array}$ & $\mathbf{N}$ & $\begin{array}{l}\text { Pre-Treatment Deviation } \\
\text { (PD) }\end{array}$ & $\begin{array}{l}\text { Post-Treatment Deviation } \\
\text { (PD) }\end{array}$ & $\begin{array}{l}\text { Mean Reduction } \\
\text { (PD) }\end{array}$ & $\begin{array}{l}\text { Percentage of } \\
\text { Improvement }\end{array}$ \\
\hline 2.5 & 8 & $16.1 \pm 2.16$ & $7.6 \pm 6.8$ & 8.5 & $32.1 \pm 41.2$ \\
5 & 16 & $25 \pm 7$ & $12.3 \pm 9.1$ & 12.6 & $35 \pm 39$ \\
7.5 & 7 & $32.5 \pm 3.8$ & $12.5 \pm 10.5$ & 19.9 & $57.1 \pm 30.4$ \\
10 & 25 & $56.3 \pm 12.4$ & $25.7 \pm 18.7$ & 30.6 & $45 \pm 31.4$ \\
\hline
\end{tabular}

Table 6 The Mean Pre-Treatment and Post-Treatment Deviations, Mean Reduction and Percentage of Improvement from Initial Deviations ( \pm Standard Deviation) with Regard to the Change in Diagnosis

\begin{tabular}{|l|l|l|l|l|l|}
\hline Diagnosis & N & $\begin{array}{l}\text { Pre-Treatment } \\
\text { Deviation (PD) }\end{array}$ & $\begin{array}{l}\text { Post-Treatment } \\
\text { Deviation (PD) }\end{array}$ & $\begin{array}{l}\text { Mean } \\
\text { Reduction (PD) }\end{array}$ & $\begin{array}{l}\text { Percentage of } \\
\text { Improvement }\end{array}$ \\
\hline Infantile ET & 24 & $52.1 \pm 16.8$ & $23.3 \pm 18.5$ & $28.8 \pm 15.9$ & $57.7 \pm 31.5$ \\
PAET & 22 & $29 \pm 14.7$ & $12.3 \pm 13.4$ & $16.7 \pm 14.6$ & $56.2 \pm 38$ \\
Sensory ET & 4 & $34.5 \pm 13$ & $15.6 \pm 12.3$ & $18.75 \pm 21.9$ & $44.2 \pm 41.4$ \\
PAET with a high AC/A ratio & 2 & $22.5 \pm 3.53$ & $18.5 \pm 9.2$ & $4 \pm 5.6$ & $20 \pm 28.2$ \\
Duane retraction syndrome type I & 2 & 20 & $16 \pm 2.8$ & $4 \pm 2.8$ & $20 \pm 14.1$ \\
Bilateral sixth nerve palsy & $\mathrm{I}$ & 35 & 10 & 25 & 71.4 \\
Nonrefractive accommodative ET & $\mathrm{I}$ & 25 & 18 & 7 & 28 \\
\hline
\end{tabular}

Abbreviations: ET, esotropia; PAET, partially accommodative esotropia; AC/A, accommodative convergence/accommodation.

Table 7 Dose and Lid Position in First Visit

\begin{tabular}{|l|l|l|l|}
\hline Dose & N (\%) & Normal N (\%) & Ptosis N (\%) \\
\hline $2.5 \mathrm{IU}$ & $814.3 \%$ & $562.5 \%$ & $337.5 \%$ \\
$5 \mathrm{IU}$ & $1628.6 \%$ & $743.75 \%$ & $956.3 \%$ \\
$7.5 \mathrm{IU}$ & $712.5 \%$ & $457.14 \%$ & $342.9 \%$ \\
$10 \mathrm{IU}$ & $2544.6 \%$ & $1248 \%$ & $1352 \%$ \\
\hline
\end{tabular}

achieved with the smallest range of deviation $(66 \%)$, and the lowest with the largest range of deviation $(10 \%)$. The second and third groups had success rates of $36 \%$, and $33 \%$, respectively. ${ }^{9}$ Our higher success rate in each similar group in regard to the range of deviation $(75 \%$, $37.5 \%, 42.8 \%$, and $28 \%$ ) could be explained by the method used, as we increased the BTA dose by 2.5 IU for each $10 \mathrm{PD}$ increase in deviation. Besides, unlike Abbasoglu et al's study, the use of a second BTA injection was defined, in this study, as a failed outcome. However, there is a debate on the conversion ratio between Botox ${ }^{\circledR}$ and dysport ${ }^{\circledR}$ which ranges from 1:1 to $1: 11,{ }^{10,11}$ meaning that 1 unit of Botox ${ }^{\circledR}$ might not be equal to 1 unit of dysport $^{\circledR}$ in potency, leading to different results in angle correction. ${ }^{10,11}$

In this study, the dose-effect of BTA on the percentage of improvement in deviation showed similar outcomes to
Abbasoglu et al's study, as higher doses gave higher percentages of improvement. Abbasoglu et al investigated the effect of increasing the dose on the percentage of improvement in deviation once they had failed outcomes. ${ }^{9}$ The dose-effect of BTA was increased by increasing the dose from $2.5 \mathrm{IU}$ to $10 \mathrm{IU}(30.2 \pm 4.4$ vs $53.7 \pm 9.1$, respectively) and from 2.5 IU to $20 \mathrm{IU}(30.2 \pm 4.4$ vs $56.3 \pm 8.1$, respectively). ${ }^{9}$ In this study, we set a range of deviation for which a specific dose of BTA was given. The percentages of improvement achieved with $2.5 \mathrm{IU}$ and $10 \mathrm{IU}$, were $32.1 \pm 41.2$ and $45 \pm 31.4$, respectively. This emphasizes that the larger the dose the higher is the percentage of improvement in deviation. However, it is worth mentioning that in comparison to large deviations, smaller percentages of improvement in small deviations would qualify them as successful.

Among the different diagnoses of esotropia, PAET achieved the highest success rate $(59.1 \%$, p-value: 0.13$)$ in this study. We had 22 patients with PAET and the mean pre-treatment angle of deviation was $29 \pm 14$.7. Solebo et al had 15 patients with nonaccommodative and PAET. A standard dose of $2.5 \mathrm{IU}$ of BTA (Dysport ${ }^{\circledR}$ ) in $0.1 \mathrm{~mL}$ of saline was administered in each muscle. The median pretreatment angle of deviation was 40 PD. Successful outcomes (less than 11 PD 6 months post BTA injection) were 
seen in $53 \%$ of the patients. ${ }^{12}$ In Al Taisan et al's study, all patients with different types of strabismus were given 2.5 to $10 \mathrm{IU}$ of BTA (Botox ${ }^{\circledR}$ ) depending on the surgeon's preference and his/her own experience. An average of 1.2 BTA injections was given. PAET showed a $70.6 \%$ success rate ( $\mathrm{n}=24$ out of 34 patients), which was the highest among the different diagnoses involved in their study, defined as an angle of deviation $\leq 10$ at least 4 months post-treatment. ${ }^{7}$ Our finding was consistent with the previous studies where PAET showed the highest rate of successful outcomes. This could be explained by the role the refractive accommodation plays in this type of strabismus, in addition to the presence of fusion as PAET develops in older children in comparison to infantile esotropia.

In regard to infantile esotropia, our results $(29.2 \%$ success rate) were not very consistent with others. Solebo et al had 10 patients with infantile esotropia in the study. All the patients were given 2.5 IU of BTA $\left(\right.$ Dysport $^{\mathbb{B}}$ ) in $0.1 \mathrm{~mL}$ of saline. The median pretreatment deviation was 40 PD (range 18-80 PD). 20\% had successful outcomes. ${ }^{10}$ However, their small sample size could contribute to their lower rate of success. Chen et al had 24 patients with infantile esotropia who were given 2.5-3.75 IU of BTA in $0.03 \mathrm{~mL}$ of saline. ${ }^{12}$ The type of BTA used was not documented in the study. Successful outcomes $(<10$ PD 6 months post-treatment $)$ were achieved in $37.5 \%{ }^{13}$ The mean pre-treatment deviation was $33.9 \pm 16.7$ vs $52.1 \pm 16.8$ in this study. This difference in the mean deviation might contribute to our lower success rate. Although a reduction in the amount of angle deviation to within $20 \mathrm{PD}$, which was the definition of a partially successful outcome in Cochrane systematic review, ${ }^{5}$ was seen in $54.2 \%$ of patients with infantile esotropia in this study, this was not considered a successful treatment as we aimed to reach a successful outcome using a single BTA injection. Given that infantile esotropia is known to cause a large angle of deviation, which also applies to this study, it showed the highest percentage of improvement $(57.7 \pm 31.5)$ and the highest mean reduction in deviation $(28.8 \pm 15.9)$, as there was a larger room for improvement in comparison to the other diagnoses. Taking into consideration what is mentioned before, a second injection of BTA might be effective and sufficient in reaching straight eyes. Thus, BTA can be used as a stand-alone therapy for patients with infantile esotropia who are aware of the success rate and want to try a non-incisional intervention or to debulk the angle before surgery. ${ }^{14}$ Considering doses higher than $10 \mathrm{IU}$ in patients with an angle of deviation $\geq 40 \mathrm{PD}$, or multiple BTA injections would be a possible considerable option.

Tejedor and Gutiérrez-Carmona had 48 patients with PAET with a high AC/A ratio where 2.5-3 IU of BTA $\left(\right.$ Botox $^{\circledR}$ ) was administered in all the patients. The average angle of deviation was not documented. A successful outcome was defined as deviation $\leq 8$ PD 6 months post-BTA injection where $93.7 \%$ met the criteria for success. ${ }^{15}$ In our study, two patients had PAET with a high AC/A ratio and one patient had nonrefractive accommodative esotropia where all showed failed outcomes. This could be due to the small number of patients in our study.

One patient in this study had bilateral sixth nerve palsy who responded well to the predesignated dose of BTA (7.5 IU) for his angle of deviation (35 PD). Solebo et al had five patients with sixth nerve palsy. The median angle of deviation was 50 PD and all of them were given a standard dose of $2.5 \mathrm{IU}$ of BTA (Dysport ${ }^{\circledR}$ ) in $0.1 \mathrm{~mL}$ of saline. Only one patient had a successful outcome. ${ }^{12}$ The fact that a higher dose was given in this study might explain the higher success rate in comparison to Solebo et al's study. However, we had only one patient with sixth nerve palsy which renders the comparison with other studies unreliable.

Duane retraction syndrome type 1 showed failed outcomes in our study, which is consistent with Solebo et al's study. ${ }^{12}$ Ameri et al had 16 patients with Duane retraction syndrome type 1. 3.5 IU of Novotox Ultra ${ }^{\mathrm{TM}}$ was given for all the patients. $37.5 \%(\mathrm{n}=6)$ showed successful outcomes defined in their study as a residual deviation $\leq 8$ PD and a residual face turn $<5$ degrees. The success rate was significantly related to the amount of muscle restriction found in the forced duction test, as more restriction detected before BTA injection was a prediction for a higher rate of successful outcomes (p: 0.019). ${ }^{16}$ The comparison between Ameri et al's study and our study is compromised by the smaller sample attained in the latter study, in addition to the difference in the type of Botulinum toxin given and the lack of studies comparing Novotox Ultra ${ }^{\mathrm{TM}}$ with Botox $^{\circledR}$, as Novotox Ultra $^{\mathrm{TM}}$ is a new, unlicensed, and look-alike BTA product. Yet, the failure in our sample could be explained by the fact that this is a restrictive type of strabismus, which may need a higher dose than the usual doses given for comitant esotropia with a similar angle of deviation.

Scott et al had 14 patients with esotropia and an average of 1.7 BTA injections was given. Four patients had prior incisional strabismus surgery where $29 \%$ had 
successful outcomes. ${ }^{8}$ In this study, four patients had sensory esotropia, only one of those (25\%) showed a successful outcome. This could be explained by the absence of fusion which renders a poor prognosis for reaching and stabilizing the ocular alignment in the sensory type of esotropia.

The incidence of ptosis post-BTA injection in this study was $50 \%$ which is within the reported range (20$50 \%$ ). However, different factors might contribute to this wide range, such as the type of BTA, dose, rectus muscle injected, and small ptosis that can be overlooked. ${ }^{12,13,17}$ In our study, $37.5 \%(n=3)$ of the patients in the first group who received 2.5 IU of BTA developed post-treatment ptosis evident in the first visit, which is the smallest percentage among the other groups. This fact may emphasize the importance of determining the smallest effective dose for each range of angle deviation, as to decrease the chance of possible BTA complications.

\section{Limitations}

The limitations of our study included the small sample size and the lack of a control group (ie patients who underwent surgery as an initial intervention or who had a fixed dose for all angles of deviation). Another drawback was the absence of the initial stereopsis measurements and the degree of stereopsis restoration after BTA injections. Also, the lack of the angle measurements after the second BTA injection makes the data about the efficacy of a second BTA injection limited.

\section{Conclusion}

Using dose increments according to the amount of angle deviation can be considered efficient and cost-effective as a primary treatment (in certain types of esotropia), especially for those with PAET. In addition, the incidence of BTA injection-associated complications could be less when such an approach is used. Future studies using a similar method and having a larger number of patients with a control group are recommended to have a better prediction of the outcome.

\section{Disclosure}

The authors report no conflicts of interest in this work.

\section{References}

1. Comella CL, Pullman SL. Botulinum toxins in neurological disease. Muscle Nerve. 2004;29(5):628-644. doi:10.1002/mus.20033

2. Jankovic J. Botulinum toxin in clinical practice. J Neurol Neurosurg Psychiatry. 2004;75(7):951-957. doi:10.1136/jnnp.2003.034702

3. Scott AB. Botulinum toxin injection of eye muscles to correct strabismus. Trans Am Ophthalmol Soc. 1981;79:734-770.

4. Dutton JJ, Fowler AM. Botulinum toxin in ophthalmology. Surv Ophthalmol. 2007;52(1):13-31. doi:10.1016/j.survophthal.2006.10.003

5. Rowe FJ, Noonan CP. Botulinum toxin for the treatment of strabismus (Review). Cochrane Database Syst Rev. 2017;3.

6. Talebnejad MR, Tahamtan M, Nowroozzadeh MH. Botulinum toxin injection for treatment of acute traumatic superior oblique muscle palsy. $J$ Ophthalmic Vis Res. 2015;10(3):263-267. doi:10.4103/2008-322X.170350

7. Al Taisan AA, Al Shamlan FT, Al Mulhim AK, Alsomali AI, Al Owaifeer AM. Botulinum toxin; indications, success rates and complications in the management of horizontal strabismus in Saudi Arabia. J Clin Ophthalmol. 2018;02(01). doi:10.35841/clinicalophthalmology.2.1.32-37

8. Scott AB, Magoon EH, McNeer KW, Stager DR. Botulinum treatment of childhood strabismus. Ophthalmology. 1990;97 (11):1434-1438. doi:10.1016/S0161-6420(90)32390-4

9. Abbasoglu OE, Sener EC, Sanac AS. Factors influencing success and dose-effect relation of botulinum A treatment. Eye. 1996;10 (3):385-391. doi:10.1038/eye.1996.78

10. Wohlfarth K, Göschel H, Frevert J, Dengler R, Bigalke H. Botulinum A toxins: units versus units. Naunyn Schmiedebergs Arch Pharmacol. 1997;355(3):335-340. doi:10.1007/PL00004951

11. Marchetti A, Magar R, Findley L, et al. Retrospective evaluation of the dose of Dysport and BOTOX in the management of cervical dystonia and blepharospasm: the REAL DOSE study. Mov Disord. 2005;20(8):937-944. doi:10.1002/mds.20468

12. Solebo AL, Austin AM, Theodorou M, Timms C, Hancox J, Adams GGW. Botulinum toxin chemodenervation for childhood strabismus in England: national and local patterns of practice. PLoS One. 2018;13(6):1-12. doi:10.1371/journal.pone.0199074

13. Chen J, Deng D, Zhong H, et al. Botulinum toxin injections combined with or without sodium hyaluronate in the absence of electromyography for the treatment of infantile esotropia: A pilot study. Eye. 2013;27(3):382-386. doi:10.1038/eye.2012.264

14. de Alba Campomanes AG, Binenbaum G, Eguiarte GC. Comparison of botulinum toxin with surgery as primary treatment for infantile esotropia. J AAPOS. 2010;14(2):111-116. doi:10.1016/j.jaapos.2009.12.162

15. Tejedor J, Gutiérrez-Carmona FJ. Botulinum toxin in the treatment of partially accommodative esotropia with high AC/A ratio. PLoS One. 2020;15(2):e0229267. doi:10.1371/journal.pone.0229267

16. Ameri A, Farzbod F, Bazvand F, et al. Botulinum toxin injection in the patients with Duane syndrome type 1. J Curr Ophthalmol. 2017;29(1):50-53. doi:10.1016/j.joco.2016.09.004

17. Tejedor J, Rodríguez JM. Early retreatment of infantile esotropia: comparison of reoperation and botulinum toxin. $\mathrm{Br} J$ Ophthalmol. 1999;83(7):783-787. doi:10.1136/bjo.83.7.783 


\section{Publish your work in this journal}

Clinical Ophthalmology is an international, peer-reviewed journal covering all subspecialties within ophthalmology. Key topics include: Optometry; Visual science; Pharmacology and drug therapy in eye diseases; Basic Sciences; Primary and Secondary eye care; Patient Safety and Quality of Care Improvements. This journal is indexed on PubMed
Central and CAS, and is the official journal of The Society of Clinical Ophthalmology (SCO). The manuscript management system is completely online and includes a very quick and fair peer-review system, which is all easy to use. Visit http://www.dovepress.com/ testimonials.php to read real quotes from published authors.

Submit your manuscript here: https://www.dovepress.com/clinical-ophthalmology-journal 